\title{
Fluorimetric method for simultaneous estimation of cortisol, corticosterone, and testosterone in plasma
}

\author{
D MATTINGLY, H MARTIN, CHRISTINE TYLER The Postgraduate Medical School, University \\ of Exeter
}

SUMMARY The simultaneous estimation of steroids in plasma was carried out by the assay of cortisol, corticosterone, and testosterone. The method entails separation by means of thin layer chromatography, followed by conversion to a fluorophore and fluorimetric measurement. Its major advantages are its high specificity, its ability to detect unknown substances, and the ease with which it can be performed. The method has acceptable levels of accuracy and precision and the normal values obtained by it compare well with those given by methods in general use.

Numerous methods have been described for the determination of steroids in blood based on fluorimetry, radioimmunoassay (RIA), competitive protein binding (CPB), high performance liquid chromatography (HPLC), or enzyme immunoassay (EIA). Most of them, however, have the disadvantage that their specificities are not absolute because a certain amount of interference or cross-reactivity with other steroids may occur. This can be a major drawback when the configuration of the substance under study is in doubt.

We developed a method involving thin layer chromatography (TLC), followed by conversion to a fluorophore and fluorimetric detection, in which individual steroids are completely separated and are measured simultaneously. This is a modification and extension of the method first described by Hamman and Martin in $1969^{\prime}$ for the assay of cortisol and corticosterone. The present paper is restricted to the validation of the method for the simultaneous assay of cortisol, corticosterone, and testosterone, but there is no doubt that many other steroids can be measured in this way.

\section{Material and methods}

The following material, obtained from $\mathrm{BDH}$, UK, was used: benzene AR; methanol AR; methylene chloride (reagent grade) purified in the laboratory ${ }^{2}$; sulphuric acid. Steroid standards were purchased from Sigma Chemicals, Poole, Dorset.

\section{SPECIAL EQUIPMENT}

1 Glass tubes with ground glass stoppers, volume $19 \mathrm{ml}$,

Accepted for publication 12 January 1989 treated with a silicone solution to reduce absorption of steroids on glass were used. All glassware should be cleaned with a non-fluorescent detergent such as Decon 90 (Decon Laboratories Ltd, Hove, Sussex). 2 Spectrophotofluorimeter with TLC scanning attachment (Aminco-Bowman 4-8911E, VA Howes, London) was adapted by us so as to increase the sensitivity. In the unmodified instrument the fluorescence emitted from the steroid spot on the layer passes through the glass plate before collection by the fibre optic. This arrangement was changed so that the fibre optic was positioned on the same side of the plate as the incident light, and at an angle of $45^{\circ}$ to it. Thus the emitted fluorescence was collected directly from the surface of the layer without passing through the plate. The excitation slit width is $0.5 \mathrm{~mm}$ and the photomultiplier slit width is $1.0 \mathrm{~mm}$. The wavelength of the exciting light is $470 \mathrm{~nm}$, and that of the emitted light is $520 \mathrm{~nm}$ when cortisol, corticosterone, and testosterone are under study. The wavelengths may need to be varied slightly for other steroids.

3 Chart recorder (Bryan model No 24000 A3, VA Howes, London) was used.

4 Glass plates for thin layer chromatography measured $20 \times 5 \times 0.3 \mathrm{~cm}$. These are spread with silica gel (MN Kieselgel G-HR, Camlab, Cambridge) to produce a layer with a thickness of $200 \mu \mathrm{m}$. Five lanes $4 \mathrm{~mm}$ wide are scribed into the layer along the length of the plate so that four specimens and a standard can be run together. Additional lines are scribed close to the sides of the plate to minimise edge evaporation effects. A horizontal line is scribed across the plate at the required run distance (usually $14.7 \mathrm{~cm}$ ).

5 The glass chromatography jar measured $30 \times 10 \mathrm{~cm}$. 6 A planimeter (Allbrit, WF Stanley, London) for measuring area under curve on scan trace was also used. 
Blood is taken into standard lithium heparin tubes (Searle Pharmaceuticals, High Wycombe, Buckinghamshire) and centrifuged immediately. The plasma is either used at once or deep-frozen until use. Plasma $(2 \mathrm{ml})$ is pipetted on to $15 \mathrm{ml}$ of methylene chloride in a stoppered tube of $19 \mathrm{ml}$ volume. The tube is rotated horizontally for 20 minutes to extract the steroids into the solvent. ${ }^{2}$ The plasma layer is aspirated and discarded. A $13 \mathrm{ml}$ aliquot of the solvent phase is transferred to a clean tube and evaporated to dryness in a water bath at $50^{\circ} \mathrm{C}$, under a stream of nitrogen (99.99\% pure, British Oxygen Company, UK).

The residue in the tube is dissolved with three drops of methylene chloride which is spotted on to a lane on the plate at a distance of $3 \mathrm{~cm}$ from the bottom of the layer. The tube is further washed with two drops and then with one drop of methylene chloride which are added to the spot on the plate. During this procedure the chromatography plate is placed on a warmed metal surface to accelerate evaporation of the spotting solvent.

The lower end of the TLC plate is immersed to a depth of $2 \mathrm{~cm}$ in the running solvent, benzenemethanol (50:5), in the chromatography jar. The solvent is allowed to ascend to the horizontal line scribed in the layer and the plate is then dried in a current of air. This running procedure is repeated a second time to produce a better separation of the steroid spots. Fluorescence is induced by spraying the plate with $20 \%$ sulphuric acid in water, using a pressurised cannister to create a fine mist, until the layer is visibly and evenly damp all over.

The plate is then heated on a metal block in a hot air oven at $80^{\circ} \mathrm{C}$ for 30 minutes. After heating, the plate is cooled in air for 15 minutes to allow the fluorescence to develop, then placed layer downward in the TLC scanner. Each lane in turn is passed above the slit of exciting light and the fluorescence emitted is recorded as a series of peaks on paper. The scanning of five lanes should be completed within 20 minutes, during which time the fluorescence remains constant. The area under the peak on the scan trace is measured by means of a planimeter.

A mixture of standard steroids in water $(2 \mathrm{ml})$ containing cortisol $607.2 \mathrm{nmol} / 1(22 \mu \mathrm{g} / 100 \mathrm{ml})$, corticosterone $57.8 \mathrm{nmol} / 1(2.0 \mu \mathrm{g} / 100 \mathrm{ml})$, and testosterone $17.4 \mathrm{nmol} / \mathrm{l}(500 \mathrm{ng} / 100 \mathrm{ml})$ is taken through the method alongside the plasmas under investigation. The testosterone concentration was reduced to 1.73 $\mathrm{nmol} / 1(50 \mathrm{ng} / 100 \mathrm{ml})$ if female plasmas were being assayed. Estimations can be completed within one working day.

Normal values for cortisol, corticosterone, and testosterone were obtained from members of the hospital staff and adult hospital patients. Patients with known endocrine, liver, or renal disease were excluded, and none of the patients was acutely ill at the time or being subjected to stressful procedures. Blood was taken in the morning between $0800-1000$ hours to avoid variations due to circadian rhythm.

\section{Results}

RELATIVE FRACTION (RF) VALUES

As we were particular concerned with cortisol, corticosterone, and testosterone the running solvent benzene-methanol (50:5) was chosen for the good separation it gave with these steroids, but it is possible to measure the concentration of other fluorogenic steroids with intermediate RF values at the same time (table 1). A typical record of the scan for cortisol, corticosterone, and testosterone is shown in fig 1 . A running solvent such as chloroform-acetone-water $(42: 18: 0.5)$ can be used to give a better separation of steroids with lower RF values. When steroids with an RF value of more than 0.6 are under investigation defatting of the plasma may be necessary to produce a stable baseline. ${ }^{3}$

\section{DEVELOPMENT OF FLUORESCENCE}

Most steroids do not fluoresce naturally but many will produce fluorophores when reacted with strong acids or alkalis. For the steroids under investigation here the most satisfactory method is to spray the plates with $20 \%$ sulphuric acid, followed by heating in a hot air oven at $80^{\circ} \mathrm{C}$ for 30 minutes. The temperature of the oven and the time for which heating is carried out were chosen to give maximum fluorescence from cortisol, corticosterone, and testosterone. The optimum temperature and time of heating, however, do vary from

Table 1 Steroid $R \boldsymbol{F}$ values in running solvent benzene:methanol (50:5)

$6 \beta$-Hydroxycortisol

$20 \beta$-Hydroxycortisol

Prednisolone

18-Hydroxycorticosterone

$20 \beta$-Hydroxycorticosterone

Oestriol

Cortisol

Aldosterone

18-Hydroxy-deoxycorticosterone

21-Deoxycortisol

Corticosterone

Oestradiol

Testosterone

11-Deoxycortisol

11-Deoxycorticosterone

Oestrone

Dehydro-epiandrosterone

$5 \alpha$-Dihydrotestosterone

Pregnenolone

Androstenedione

Cholesterol

Spironolactone

Progesterone 

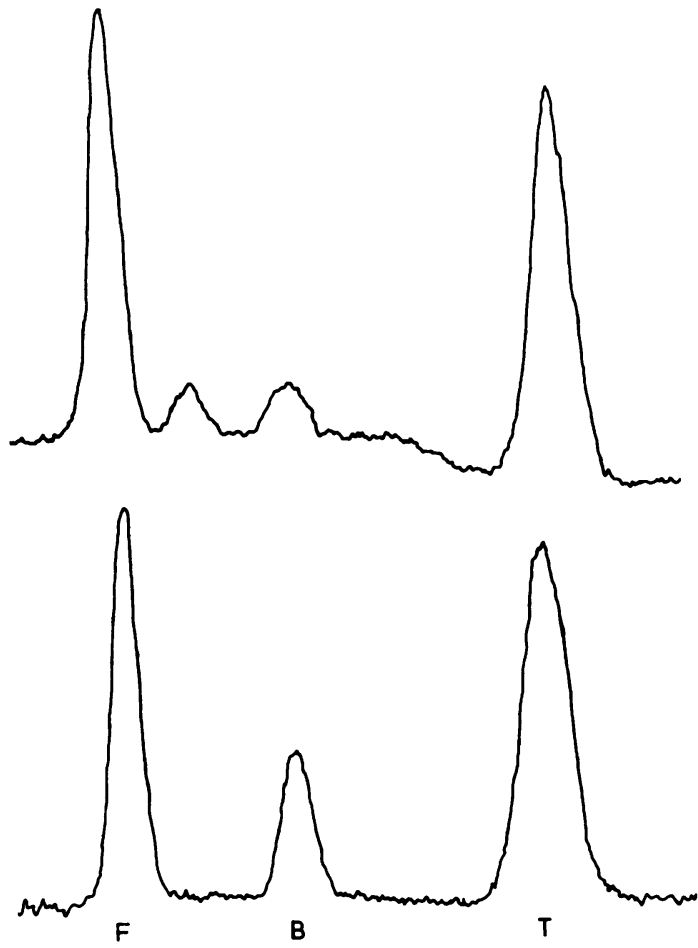

Fig 1 Typical scan given by normal male plasma (top) and steroid standards (bottom). $F=607.2 \mathrm{nmol} / \mathrm{l}(22 \mu \mathrm{g} / 100$ ml) cortisol; $B=57.8 \mathrm{nmol} / \mathrm{l}(2.0 \mu \mathrm{g} / 100 \mathrm{ml})$ corticosterone; $T=17.4 \mathrm{nmol} / \mathrm{l}(500 \mathrm{ng} / 100 \mathrm{ml})$ testosterone.

one steroid to another, and may need to be adjusted accordingly.

EXCITATION AND EMISSION WAVELENGTHS

Choice of excitation and emission wavelengths on the spectrophotofluorimeter were made on the basis of the fluorescence spectra. For most steroids the optimal settings were $470 \mathrm{~nm}$ of excitation and $520 \mathrm{~nm}$ of emission. Spectra for cortisol, corticosterone, and testosterone were virtually identical, but were distinctive for some other steroids.

\section{DOSE RESPONSE CUR VES}

There was a linear relation between the amount of steroid and the area under the curve of the peak of the scan trace. Examples of these with standard solutions of cortisol, corticosterone, and testosterone are shown in figs 2-4. The range of steroid concentrations used covered those found in plasma.

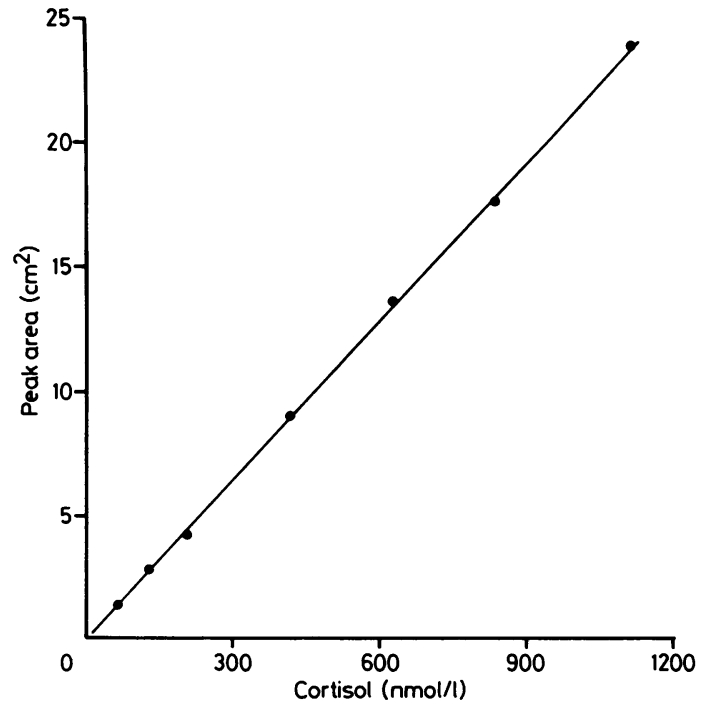

Fig 2 Dose-response curve for cortisol.

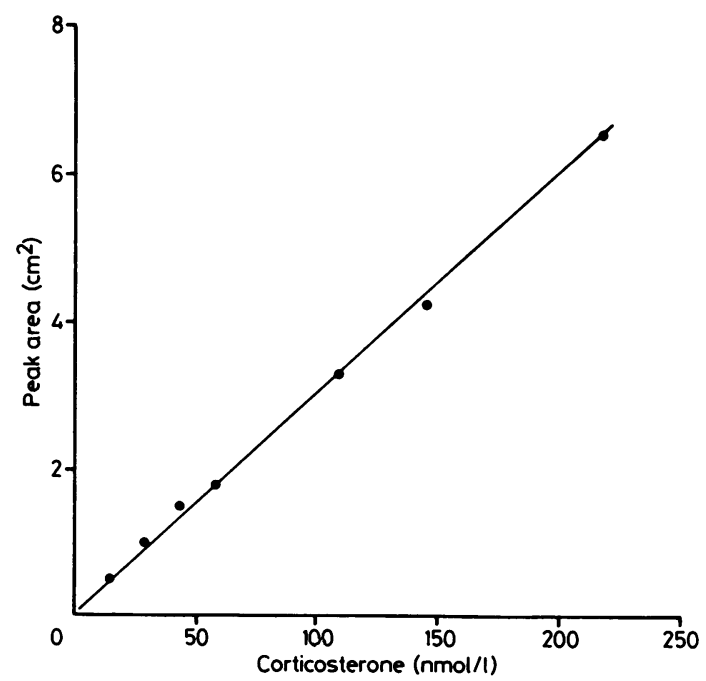

Fig 3 Dose-response curve for corticosterone.

$\mathrm{cm}^{2}$ above the baseline on the scan traces. For cortisol the lower limit of detection is $16.5 \mathrm{nmol} / \mathrm{l}$. For corticosterone it is $2.9 \mathrm{nmol} / \mathrm{l}$, and for testosterone $0.35 \mathrm{nmol} / 1$. The sensitivity of the spectrophotofluorimeter can be adjusted so that the amount of steroid $/ \mathrm{cm}^{2}$ scan trace is suitable for the sample under test.

\section{Results}

ACCURACY

The ability of the method to measure true values was 


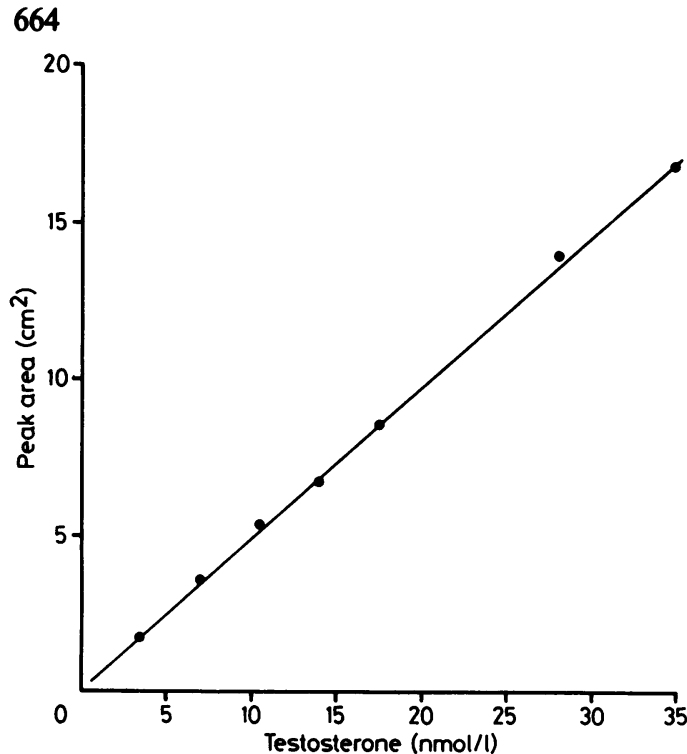

Fig 4 Dose-response curve for testosterone.

assessed by recovery experiments in which known amounts of steroid were added to the plasma before assay.

\section{PRECISION}

The precision of the method $(\mathrm{P})$ was assessed both for duplicates assayed together and for replicates measured on different days. It is expressed in terms defined by Snedecor ${ }^{4}$ as:

$$
P=\sqrt{\frac{\sum\left(d^{2}\right)}{2 N}}
$$

where $\Sigma\left(\mathrm{d}^{2}\right)=$ the sum of the squared difference between duplicates or replicate estimations, and $\mathbf{N}=$ number of paired estimations.

The results obtained by the method described here were compared with other methods in general use, by further estimations on the same plasma sample. Values for plasma cortisol were compared with the values obtained by Mattingly's fluorimetric method for 11-OHCS, ${ }^{2}$ which measures both cortisol and corticosterone, and values for plasma testosterone with an RIA method (Nordiclab kit, available from Nordiclab, Oulunsalo, Finland)

\section{CORTISOL}

The mean recovery of $8.28 \mathrm{nmol}(0.3 \mu \mathrm{g})$ of cortisol added to $2 \mathrm{ml}$ of plasma was $92.3 \%$ ( $\pm 6 \cdot 3$ (SD)), with a range of $81.7-98.1 \%$ on five estimations. The precision over our normal morning range of plasma
Mattingly, Martin, Tyler

cortisol concentration of $180-674 \mathrm{nmol} / 1$ was $\pm 17 \cdot 7$ nmol/l for 15 duplicates estimated together, and \pm $33.6 \mathrm{nmol} / \mathrm{l}$ for 10 replicates estimated on different days. There was good correlation with the results obtained on the same sample using Mattingly's fluorimetric method for 11-hydroxycorticosteroids. ${ }^{2}$ Of 26 plasma samples with concentrations within the normal range the coefficient of correlation was 0.87 .

\section{CORTICOSTERONE}

The mean recovery of $0.58 \mathrm{nmol}(20 \mathrm{ng})$ of corticosterone added to $2 \mathrm{ml}$ of plasma was $104.7 \% \pm 5.98$ (SD), with a range of $96.9-110.5 \%$ on eight estimations. The precision over our normal morning range of plasma corticosterone concentrations of 7.5-43.9 $\mathrm{nmol} / \mathrm{l}$ was $\pm 0.46 \mathrm{nmol} / \mathrm{l}$ for 12 duplicates measured together, and $\pm 0.95 \mathrm{nmol} / 1$ for 10 replicates measured on different days.

\section{TESTOSTERONE}

The mean recovery of $0.22 \mathrm{nmol}(6.4 \mathrm{ng})$ of testosterone added to $2 \mathrm{ml}$ of female plasma was $94.9 \%$ \pm 5.9 (SD), with a range of $84-102.9 \%$ on nine estimations. The precision over our range of normal plasma testosterone concentrations in women of 0.6 $3.6 \mathrm{nmol} / 1$ was \pm 0.13 (SD) $\mathrm{nmol} / 1$ for six duplicates measured together, and $\pm 0.21 \mathrm{nmol} / 1$ for six replicates measured on different days.

In the plasma of male patients, over our normal range of $11.7-40.1 \mathrm{nmol} / \mathrm{l}$, the precision was \pm 0.54 $\mathrm{nmol} / \mathrm{l}$ for nine duplicates where the pair were measured together, and $\pm 1 \cdot 21 \mathrm{nmol} / 1$ for six replicates measured on different days.

The results of 28 estimations were compared with those obtained on the same sample by the RIA Nordiclab method. The correlation coefficient was 0.88 , which is satisfactory considering that this RIA method also measures small amounts of other steroids.

\section{NORMAL VALUES}

In 45 normal subjects the range of morning plasma cortisol concentrations was $180-674 \mathrm{nmol} / \mathrm{l}$, with a mean of $365 \pm 127(\mathrm{SD}) \mathrm{nmol} / \mathrm{l}$. For corticosterone, the range was $7.5-43.9 \mathrm{nmol} / 1$, with a mean of $21.7 \pm$ $8 \cdot 1$ (SD) $\mathrm{nmol} / \mathrm{l}$. For testosterone, subjects were divided according to sex. In 23 men the concentrations ranged from $11 \cdot 7-40 \cdot 1 \mathrm{nmol} / \mathrm{l}$, with a mean of $23.8 \pm$ 9.4 (SD) $\mathrm{nmol} / \mathrm{l}$. In 22 women the range was from 0.6 $3.6 \mathrm{nmol} / \mathrm{l}$, with a mean of $1.73 \pm 0.7$ (SD) $\mathrm{nmol} / \mathrm{l}$.

\section{ABNORMAL VALUES}

The method was also applied to plasma from patients expected to have concentrations outside the normal range. For example, plasma from a 19 year old girl 
with untreated Addison's disease showed a cortisol concentration of only $41.4 \mathrm{nmol} / 1$ with no detectable corticosterone; in a 65 year old man with a bronchial carcinoma and the ectopic ACTH syndrome the cortisol and corticosterone concentrations were grossly raised to $3920 \mathrm{nmol} / 1$ and $702 \mathrm{nmol} / \mathrm{l}$, respectively.

In 10 untreated hypogonadal men the plasma testosterone concentration ranged from undetectable to $6.9 \mathrm{nmol} / \mathrm{l}$. After an oral dose of $40 \mathrm{mg}$ of testosterone undecanoate (Restandol-Organon) it rose to a peak between two and four hours after ingestion. This maximal concentration varied between 6.0 and $27.7 \mathrm{nmol} / 1$ with a mean of $17.9 \mathrm{nmol} / \mathrm{l}$.

\section{Discussion}

The major advantages of the method described are its high specificity, its ability to detect unknown substances, and the rapidity with which results can be obtained. The criteria used to establish identity are the chromatographic behaviour of the individual steroids in different running solvents, their fluorescence spectra, and the conditions under which the fluorophores are produced. The non-production of a fluorophore in solution does not necessarily preclude its development on the TLC plate. Thus testosterone, unlike cortisol and corticosterone, gives no fluorescence when reacted with ethanolic sulphuric acid in solution at room temperature, but produces noticeable fluorescence when heated after development on a TLC plate.

The high specificity of this technique also avoids inaccuracies due to the cross-reactivity which occurs in most competitive protein binding (CPB) and RIA methods. This can be both substantial and variable. For example, prednisolone is a major source of interference in RIA assays for serum cortisol, but this cross-reactivity may vary between 22 and $60 \%$, depending on the method used. ${ }^{5}$ Prednisolone and several other steroids such as progesterone and 11-deoxycortisol interfere with CPB assays. Under most circumstances these interferences are unimportant in view of the usually higher concentration of circulating cortisol. This is not the case in patients taking prednisone or prednisolone, however, where misleading high results will conceal any underlying adrenocortical deficiency. Similarly, the interference produced by high progesterone activities in pregnancy, or of 11 deoxycortisol in the metyrapone stimulation test, will give erroneous results if CPB methods are used.

The Nordiclab (1982) RIA method for the estimation of testosterone, with which our results are compared, is also subject to inaccuracy. Both $5 \alpha$ dihydrotestosterone and $5 \beta$-dihydrotestosterone give significant amounts of cross-reaction $(30 \%$ and $25 \%$, respectively), while some other androgens cross-react less strongly. Such unwanted reactivity can be iden- tified and avoided by using the method described here.

Any new method, whatever its advantages, must also have acceptable values for accuracy and precision, its sensitivity must be adequate for the samples under test, and the results obtained should compare with those using other established techniques. This method satisfies these criteria on all counts. The accuracy and precision are comparable with those of methods in general use, and the sensitivity is such that concentrations below the normal ranges can be measured.

The agreement of results obtained on identical samples by this and another established technique were excellent. In the case of cortisol, in 26 plasma samples assayed by the present method, and for 11OHCS by the Mattingly method, the coefficient of correlation was 0.87 . Because the latter method measures both cortisol and corticosterone, this value, slightly below unity, reflects a good agreement between the two methods. For testosterone, comparison was made with an established RIA method in general use (Nordiclab). Here again, the agreement was good with a coefficient of correlation of 0.88 on 28 plasma samples. For corticosterone, where we had no access to an alternative method of assay, it was impossible to make a direct comparison, but from data on precision, accuracy, and recovery there is no reason to believe that it is any less satisfactory than those for cortisol and testosterone. Finally, the normal values obtained by this method for all three steroids are in good agreement with those of other workers (tables 2-5).

Table 2 Morning plasma cortisol concentrations in normal adults (nmol/l)

\begin{tabular}{lllll}
\hline Reference & Method & No & \multicolumn{2}{c}{ Mean (range) } \\
\hline Newsome et al $1972^{6}$ & CPB & 11 & 339 & $(248-428)$ \\
West et al $1973^{7}$ & RIA & 30 & 381 & $(110-662)$ \\
Gore and Lester $1975^{8}$ & CPB & 54 & 395 & $(163-627)$ \\
$\begin{array}{l}\text { Matsumura 1980 } \\
\text { Urhausen and Kinderman }\end{array}$ & RIA & 33 & 436 & $(339-533)$ \\
$\quad 1987^{10}$ & RIA & 8 & 337 & $(190-486)$ \\
Present study & & 45 & 365 & $(180-674)$ \\
\hline
\end{tabular}

Cortisol nmol $/ 1 \times 0.0362=\mu \mathrm{g} / 100 \mathrm{ml}$

Table 3 Morning plasma corticosterone concentrations in normal adults (nmol/l)

\begin{tabular}{|c|c|c|c|}
\hline Reference & Method & No & Mean (range) \\
\hline $\begin{array}{l}\text { West et al } 1973^{7} \\
\text { Matsumura } 1980^{9} \\
\text { Holsboer et al } 1982^{11} \\
\text { Wilens et al } 1984^{12} \\
\text { Oka et al } 1987^{13} \\
\text { Present study }\end{array}$ & $\begin{array}{l}\text { RIA } \\
\text { RIA } \\
\text { RIA } \\
\text { RIA } \\
\text { HPLC }\end{array}$ & $\begin{array}{r}30 \\
33 \\
6 \\
6 \\
20 \\
45\end{array}$ & $\begin{array}{l}15 \cdot 3(2 \cdot 3-31 \cdot 5) \\
24 \cdot 0(7 \cdot 8-40 \cdot 2) \\
14 \cdot 7(7 \cdot 2-24 \cdot 3) \\
11 \cdot 6(8 \cdot 7-14 \cdot 7) \\
11 \cdot 3(6 \cdot 6-15 \cdot 9) \\
21.7(7 \cdot 5-43 \cdot 9)\end{array}$ \\
\hline
\end{tabular}

Corticosterone $\mathrm{nmol} / 1 \times 0.0346=\mu \mathrm{g} / 100 \mathrm{ml}$. 
Table 4 Plasma testosterone concentrations in normal men (nmol/l)

\begin{tabular}{|c|c|c|c|}
\hline Reference & Method & No & Mean (range) \\
\hline $\begin{array}{l}\text { Ahmed } 1973^{14} \\
\text { Williams et al } 1974^{15} \\
\text { Vermeulen } 1976^{16} \\
\text { Bassett } 1980^{17} \\
\text { Shieh et al } 1987^{18} \\
\text { Present study }\end{array}$ & $\begin{array}{l}\text { CPB } \\
\text { RIA } \\
\text { RIA } \\
\text { RIA } \\
\text { EIA }\end{array}$ & $\begin{array}{l}12 \\
16 \\
31 \\
10 \\
19 \\
23\end{array}$ & 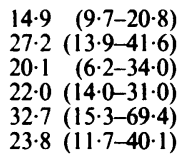 \\
\hline
\end{tabular}

Testosterone $\mathrm{nmol} / 1 \times 28.8=\mathrm{ng} / 100 \mathrm{ml}$.

Table 5 Plasma testosterone concentrations in normal women ( $\mathrm{nmol} / \mathrm{l})$

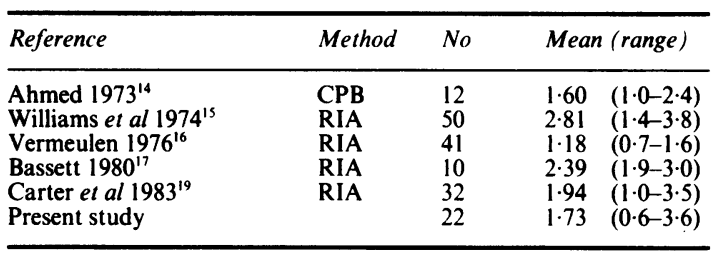

Testosterone $\mathrm{nmol} / \mathrm{l} \times 28.8=\mathrm{ng} / 100 \mathrm{ml}$.

This method has proved extremely useful in clinical practice, particularly in confirming the diagnosis of pituitary and adrenal failure in acute medical admissions. It has also been invaluable in determining the degree of absorption of oral testosterone undecanoate in the treatment of hypogonadal men. With most other assays it is only economically viable to work with large batches of specimens, whereas the method described here is cheap and quick enough for single specimens to be processed in a working day. The method also avoids the disadvantages inherent in working with radioactive materials. In particular, it avoids inaccuracies due to cross-reactivity with other naturally occurring steroids, or interference by synthetic compounds such as prednisolone.

We thank Mr J Barraclough for carrying out the radioimmunoassays of testosterone in the endocrine laboratory at the Royal Devon and Exeter Hospital. We are also indebted to the Northcott Devon Medical Foundation for financial support.

\section{References}

1 Hamman BL, Martin MM. Direct fluorescence quantitation on thin-layer chromatograms. J Lab Clin Med 1969;73:1042-8.

2 Mattingly D. A simple fluorimetric method for the estimation of free 11-hydroxycorticosteroids in human plasma. J Clin Pathol 1962;15:374-9.
3 Ismail AAA, Love DN, McKinney RWJ. Elimination of plasma lipids from steroid hormone extracts by differential solubility in water. Steroids 1972;19:689-700.

4 Snedecor GW. Queries. Biometrics 1952;8:85-8.

5 Moore A, Aitken R, Burke C, et al. Cortisol assays: guidelines for the provision of a clinical biochemistry service. Ann Clin Biochem 1985;22:435-54.

6 Newsome HH, Clements AS, Borum EH. The simultaneous assay of cortisol, corticosterone, 11-deoxycortisol and cortisone in human plasma. J Clin Endocrinol 1972;34:473-83.

7 West CD, Mahajan DK, Chavré VJ, Nabors CJ, Tyler FH. SImultaneous measurement of multiple plasma steroids by radioimmunoassay demonstratng episodic secretion. J Clin Endocrinol Metab 1973;36:1230-6.

8 Gore M, Lester E. Comparison of a fluorimetric method and a competitive protein binding assay kit for the determination of plasma hydroxycorticosteroids. Ann Clin Biochem 1975;12: $160-2$.

9 Matsumura S. The effects of ACTH, insulin hypoglycaemia, dexamethasone and metyrapone on corticosterone secretion in healthy subjects: A comparison with cortisol secretion. Folia Endocrinologica Japonica 1980;56:129-38.

10 Urhausen A, Kinderman W. Behaviour of testosterone, sex hormone binding globulin (SHBG) and cortisol before and after a Triathlon competition. Int J Sports Med 1987;8:305-8.

11 Holsboer F, Winter K, Dorr HG, Sipell WG. Dexamethasone suppression test in female patients with endogenous depression: determinations of plasma corticosterone, 11deoxycorticosterone, 11-deoxycortisol, cortisol and cortisone. Psychoneuroendocrinol 1982;7:329-38.

12 Wilens TE, Ritchie JC, Carroll BJ. Comparison of plasma cortisol and corticosterone in the dexamethasone suppression test for melancholia. Psychoneuroendocrinol 1984;9:45-55.

13 Oka K, Noguchi M, Kitamura T, Shima S. Liquid chromatography and radioimmunoassay compared for determination of cortisol and corticosterone in plasma after a dexamethasone suppression test. Clin Chem 1987;33:1639-42.

14 Ahmed J. A method for the determination of plasma testosterone by competitive protein-binding after chromatography on sephadex LH-20. Clin Chim Acta 1973;43:371-8.

15 Williams BM, Horth CE, Palmer RF. The measurement of testosterone in plasma. Clin Endocrinol 1974;3:397-410.

16 Vermeulen A. Testosterone and $5 \alpha$ androstan-17 $\beta$-ol-3-one (DHT) levels in man. Acta Endocrinol 1976;83:651-64.

17 Bassett RM. A simple chromatographic method for the radioimmunoassay of four androgenic steroids. Med Lab Sci 1980;37:31-8.

18 Shieh CC, Chang SC, Tzeng CR, Huang JJ, Nir WJ, Hong CY. Measurement of testosterone in seminal plasma, saliva and serum by solid-phase enzymeimmunoassay. Andrologia 1987; 19:614-9.

19 Carter GD, Holland SM, Alaghband-Zadeh J, Rayman G, Dorrington-Ward $\mathbf{P}$, Wise PH. Investigation of hirsutism: testosterone is not enough. Ann Clin Biochem 1983;20:262-3.

Requests for reprints to: Professor D Mattingly, Exeter Postgraduate Medical Centre, Barrack Road, Exeter EX2 5DW, England. 